\title{
An Easy Approach to Exploratory Factor Analysis: Marketing Perspective
}

\author{
Noor UI Hadja1 \\ Naziruddin Abdullaha \\ Ilham Sentosa ${ }^{a}$ \\ aUniversiti Kuala Lumpur Business School (UNIKL BIS), BangunanYayasan Selangor, \\ Jalan Raja Muda Abdul Aziz, Kg Baru, 50300 Kuala Lumpur, Malaysia \\ ${ }^{1}$ Corresponding Author Email: n_hadi1@yahoo.com / noor.ul@s.unikl.edu.my
}

\section{Doi:10.5901/jesr.2016.v6n1p215}

\section{Abstract}

The purpose of this paper is to allow researchers, instructors, and students to comprehend the nature of exploratory factor analysis (EFA) from marketing perspective. In particular, the paper offer realistic information from marketing literature on developing valid instruments and making decision regarding factor extraction, factor rotation, and factor labeling. Since the items and factors identified through EFAs are using as an input for the measurement model in second generation structural equation modeling (SEM) technique. While so doing, a pilot test was conducted and items from marketing literature were analyzed via principal component analysis (PCA) using SPSS 20, the appropriateness of data for EFA was measured through KMO and Bartlett's test of Sphericity. Based on parallel analysis three factors were extracted for further investigation. The three components explained a total of $62.6 \%$ of the variance.

Keywords: Marketing; exploratory factor analysis; structure equation modeling; parallel analysis.

\section{Introduction}

The growing trend of variance based structure equation modeling VB-SEM (PLS) and covariance based structure equation modeling CB-SEM (AMOS) in the field of marketing (see Haenlein \& Kaplan, 2004; Chin et al., 1996; Statsoft, 2013; Hair et al. 2012; Henseler et al. 2009; Jarvis et al., 2003; Hair et al. 2011; MacKenzie et al., 2005) is a focal point of this study. As structure equation models (SEM) is inspected and interpreted in two phases. In the first phase the relationship between observed items and latent variables (factors, components) are assessed to confirmed construct validity and reliability (CFA). Usually, researchers are validating the outer model (see Figure, 2) for the purpose to study that whether the theoretical correlation among variables are effectively measured by the observed variables. While so doing, researchers assessing the validity (measuring what intent to measure) and reliability (internal consistency) of the measurement models, which are done by looking for the individual item reliability, reliability of the scales, convergent validity, and discriminant validity.

To evaluate the validity and reliability of the outer model, researchers need variables which are consistently moving together. Thus, to identify such variables exploratory factor analysis is conducted. In EFA the consistent movements of observed variables are identified, considering cultural differences and research setting. Therefore, the aim of this paper is to allow researchers, instructors and students to comprehend the nature of exploratory factor analysis (EFA) from marketing perspective (missing from previous studies). Also the items and factors identified through EFA are using as an inputs for testing outer model (EFAs outputs CFA inputs). The focus of this study, however, is only on the inputs required for outer model, as the popularity of SEM in the area of marketing is a good rationalization for this study.

\subsection{Organization of the Paper}

As the paper is educational in nature, for that reason this section offers clarification of EFA and suitability of data requires for factor analysis. In section 2, we provide the main points about factor extraction and its different techniques. Section 3 with subsections describes the outcomes of EFAs with factor rotation, its methods and labeling of identified factors. Section 4, provides a comprehensive practical example of EFA from marketing perspective. The conclusion and limitation of study are included in section 5 . 


\section{Exploratory Factor Analysis (FFA)}

Exploratory factor analysis (EFA) is a statistical procedure used to reduce a large number of observed variables to a small number of "factors/components", reflecting that the clusters of variables are in common. In EFA the correlation among a group of observed variables are identified and transforms into a small number of related factors. In brief, EFA captures the groups of observed variables which are consistently moving together. In this process the consistent movements of observed variables are identified through factor extraction and factor rotation. Therefore, EFA is a useful tool for investigating the relations among observed variables and a small number of underlying factors.

\subsection{Research question}

What is the underlining structure of observe variables that create marketing performance scale? How many components or factors are involved?

\subsection{Suitability of data for factor Analysis}

As a first step, there are two main issues to take into consideration to determine whether a particular set of data is appropriate for EFA; number of samples (sample size) and the strength of the relationship between indicators (variables) Pallant (2013). The adequacy of sampling is tested through KMO (Kaiser 1970, 1974), while the strength of the relationship among variables is assessed through Bartlett's test of sphericity (Bartlett, 1954). It is worth noting that the indicators should be measured at the interval level.

\subsubsection{Kaiser Meyer Olkin (KMO)}

The adequacy of the sample is measured by KMO in SPSS. The sampling is adequate or sufficient if the value of Kaiser Meyer Olkin (KMO) is larger than 0.5 Field (2000), according to Pallant (2013) the value of KMO is 0.6 and above. Kaiser (1974) recommends a bare minimum of 0.5 and the value between 0.5 and 0.7 are mediocre, value between 0.7 and 0.8 are good, value between 0.8 and 0.9 are great and value between 0.9 and above are superb (Hutcheson \& Sofroniou, 1999).

\subsubsection{Bartlett test of Sphericity}

The strength of the relationship in SPSS can be measured by a Bartlett Test of Sphericity. It is actually a measure of a multivariate normality of set of distribution. This test also checks the null hypothesis that the original correlation matrix is an identity matrix. The significant value less than 0.05 indicates that these data do not produce an identity matrix and are thus approximately multivariate normal and acceptable for further analysis (Pallant, 2013; Field, 2000).

\section{Factor Extraction}

Factor rotation is the way of defining a small number of factors that can be used to best signify the whole of the relationship between variables. There are a number of methods that might be used to help in making decision regarding determining the smaller number of factors that should be retained. The following are the well-known techniques for factor extraction.

$>$ Kaiser's criterion

$>$ Scree test (Catell, 1996)

$>$ Parallel Analysis (Horn, 1965)

One of the most frequently used methods is known as the Eigen value rules or the Kaiser's criteria. Under this criteria, components with an Eigen value larger than 1 are retained, or factors which explain a total of $70-80 \%$ of the variance is retained, or do a screen test (Catell, 1996), plotting a plot and review the plot based on Catell criteria; as according to him keep all factors above the elbow. Similarly, Horn (1965) Horn's parallel analysis is also the best way to factor extraction. Under this method of factor extraction the Eigen values are compared with the values obtained from another statistical program called Monte Carlo PCA for parallel analysis and those factors are retained whose actual Eigen value from principal component analysis (PCA) more than that of the value are obtained from Monte Carlo PCA. 
Tabachnick and Fidell (1996) suggested that the outcomes of factor extraction are parallel regardless of which method is used. They later argue that the best way to go for factor rotation is by examining the coefficient of factors in the factor correlation matrix created by the method of oblique rotation. In this matrix, look for correlation around or above 0.32 , if no correlation surpasses 0.32 then execute orthogonal rotation method (Tabachnick and Fiddell, 2007).

There are a number of ways to proceed for factor analysis, and when and where you can use a variety of methods will contingent upon many things. For the purpose of this study, this paper will use the principal component analysis $\left(\mathrm{PCA}^{1}\right)$. Principal components analysis is an analysis, which is not a factor analysis²; but, both techniques may often give similar outcomes ${ }^{3}$.

\section{Output from EFA (Oblique Technique)}

\subsection{Communalities matrix}

The communality is the proportion of common variance within a variable. Therefore, before extraction, all of the variance associated with a variable assumed to be common variance. As the PCA work on the assumption that all the variance associated with a variables supposed to be 1 before factors extraction. Thus, this communality table/matrix gives information about how much of the variance in each item is explained. Low value 0.3 indicates that the item does not fit well with another item in its component. For example 0.462 in the extraction column of the communalities table for item 1 means that $46.2 \%$ of the variance related to this item are common. It also means that before extraction there are many factors, therefore all the communalities are 1 and all of the variance is explained by all factors. After factor extraction some of the factors are thrown away as a result some information is lost. Thus, the retained factors after factor rotation cannot explain all of the variance presents in the data, nevertheless they can explain some. Therefore, the communalities represent the degree of variance in each variable that can be explained by the retained factors after extraction.

\subsection{Component Matrix}

Component matrix displays the unrotated loading of each of the items on factors. Before making decision to retain two factors or three factors you have to look for this matrix. This shows the item loading on each factor. For example, item load above 0.4 more on factor 1 and 2, lesser number of items load on factor 3 and 4 . This recommends that a two factor solution is probable being more suitable for further investigations. But before making such decision to take two factors you have to look to pattern matrix as well, which shows the loading on each factor. For example, in 20 items, 10 items load on factor 1 , five loads on component 2 , four loads on component 3 , and two loads on component 4 . So this support above decision about retaining two factors.

\subsection{Factor Rotation}

It can be hard to name the components after extraction based on their factor loadings because PCA criteria is that the first factor / component account for the maximum part of the variance. This understanding of the factors might be hard. Therefore to interpret them, the rotation of factors assists in this process, for this reason the factors are rotated. Accordingly, factor rotation changes the pattern of the unrotated factors (as shown in component matrix) and increases the understanding of each factor, by presenting the pattern of loadings in a manner that is easier to interpret and understand (Pallant, 2013: 184).

There are two types of rotation:

$>$ Orthogonal Rotation (uncorrelated)

${ }^{1}$ PCA is an approach that can be used to extract the number of underlying factors (Pallant, 2013).

${ }^{2}$ Factor analysis (FA) an analysis which already assumed that the variables does not report $100 \%$ of the variance, meaning that the early value of communalities are not supposed to be 1 but are projected, by the squared multiple correlations of the variables with others (Reitveld and Van Hout, 1993). Thus, the pattern of loadings by the (FA) and (PCA) for extracted factors are the same substantially, nevertheless their individual quantities of explained variance differ. In principle component analysis all communalities are assumed to be 1.

${ }^{3}$ The choice between PCA and FA therefore depends on the quantity of variables and the degrees of factor loading. 
$>$ Oblique Rotation ${ }^{4}$ (correlated)

In orthogonal rotation there is no correlation between the extracted factors. Here, the results are rotated component matrix and component transformation matrix. The former matrix represents the pattern of loadings of the original indicators on retained or extracted factors. While, the second matrix provides information regarding the angle of rotation. Rotation matrix comprises similar information as the component matrix with the exception that, it is calculated after factor rotation. The format of the matrix should be considered, the suppression of loadings greater than 0.4 and the ordering variable by loading size.

In oblique rotation method there is a "correlation between the extracted factors". In this matrix the results are pattern matrix (see Table 2.3), structure matrix and component correlation matrix. The pattern matrix represents the pattern loading (regression coefficient of the items on each of the factors, here convergent validity is assessed by looking for high factor loadings of converge items). The structure matrix represents the structure of loadings (the relationship between each item and each factor, here discriminant validity is assessed by cross loadings). The component correlation matrix represents the strength of the relationship between the extracted factors / components and is thus important for choosing between orthogonal and oblique rotation.

Usually in social sciences, there is a certain amount of correlation between the factors, thus relying only on the outcomes of orthogonal rotation is the loss of valuable information if there is a correlation between factors (Costello and Osborne, 2005). According to Kim and Mueller (1978), if factors are correlated or not, it might not create a big difference in the initial phase of exploratory factor analysis. Brown $(2009$, p. 20) uses three orthogonal and two oblique rotation techniques for factor rotation and got similar results from all rotation techniques. Using Varimax (one of the method of orthogonal rotation) under the supposition of independence will create an idealistic pattern of loadings (Schmitt, 2011). He also argued that even by overlooking of the correlation between factors, the oblique rotation generally creates a correct and similar pattern of loadings. Finally, he strongly recommended that researchers must use only a method of oblique rotation, because there are usually more realistic results and also has simple statistical structure. In the same way, Costello \& Osborne (2005, p. 5) too recommend oblique rotation. Consistent with such studies, we also strongly recommend oblique rotation as in the social sciences there might be a probability of correlation between factors. Furthermore, Fabrigar et al (1999) proposed that there is no extensively ideal technique for oblique rotation, each and every one tend to create comparable results.

\subsection{Labeling of factors / components}

Labeling of each factor is possible after a clear understanding and interpreting of the pattern matrix in oblique rotation method. Hence, to interpret, understand and label the factors, look at the pattern matrix in oblique rotation method and see the pattern of loadings of converge items on each factor and identify their common theme and label the factor based on that common theme (see Table 2.4). It should be noted that the pattern matrix and structure matrix confirm construct validity (convergent validity is confirmed by pattern matrix while the structure matrix confirm discriminant validity in oblique rotation technique.

\section{Practical example}

\subsection{Exploratory Factor Analysis for Marketing}

The ten items of Marketing were subjected to principal component analysis (PCA) using SPSS. Prior to performing PCA, the suitability of data for factor analysis was assessed. The sampling is adequate if the value of KMO test is greater than 0.5 (Field, 2000; Kaiser, 1974). The Kaiser Meyer-Olkin value is 0.537 (see table, 2), exceeding the recommended minimum value of 0.5 (Kaiser 1970, 1974).

In SPSS the strength of correlation can be measured by a Bartlett Test of Sphericity. The Bartlett's Test of Sphericity for marketing is statistical significance (see table 2), supporting the factorability of the correlation matrix. The factor scores are correlated; therefore we reject the null hypothesis that the original correlation matrix is an identity matrix. Principal component analysis publicized the existence of three factors.

The total variance of $62.6 \%$ is achieved from these three factors. The first Eigen value is equal to 2.624 and explained $26.2 \%$ of the variance in the original data. The second factor Eigen value is equal to 2.049 and explains $20.4 \%$

4/n oblique rotation, pattern matrix is used for understanding and interpreting the factors Pallant (2013). 
of the variance, the third component Eigen value is equal to 1.589 and explains $16 \%$ of the variance. To support in the understanding of these three factors, oblimin rotation method from oblique rotation technique was conducted. The pattern matrix has shown the existence of unpretentious structure with three factors, representing strong item loadings (see Table, 2.3).

Table 2: Kaiser-Meyer-Olkin (KMO) and Bartlett's Test

\begin{tabular}{|c|c|c|}
\hline Kaiser Meyer Olkin Measure of Sampling Adequacy & 0.537 \\
\hline Bartlett's test of Sphericity & Approx. Chi Square & 185.540 \\
\hline & Df & 45 \\
\hline & Sig & .000 \\
\hline
\end{tabular}

Source: Own survey result

Table 2.1: Total variance explained

\begin{tabular}{|c|c|c|c|c|c|c|c|}
\hline \multirow{3}{*}{ Factor } & \multicolumn{3}{|c|}{ Initial eigenvalues } & \multicolumn{3}{c|}{ Extraction sum of squared loadings } & $\begin{array}{c}\text { Rotation sum of squared } \\
\text { loadings }\end{array}$ \\
\cline { 2 - 8 } & Total & Percent of variance & Cumulative percent & Total & percent of variance & Cumulative percent & Total \\
\hline 1 & 2.624 & 26.243 & 26.243 & 2.624 & 26.243 & 26.243 & 2.482 \\
\hline 2 & 2.049 & 20.489 & 46.731 & 2.049 & 20.489 & 46.731 & 2.085 \\
\hline 3 & 1.589 & 15.893 & 62.624 & 1.589 & 15.893 & 62.624 & 1.743 \\
\hline 4 & 1.141 & 11.415 & 74.039 & & & & \\
\hline 5 & .969 & 9.692 & 83.731 & & & & \\
\hline 6 & .592 & 5.922 & 89.653 & & & & \\
\hline
\end{tabular}

Source: Own survey result

As shown in Table 2.1 total variance of $62.6 \%$ is achieved for three factors. The first Eigen value is equal to 2.624 and explained $26.2 \%$ of the variance in the original data. The second factor Eigen value is equal to 2.049 and explains $20.4 \%$ of the variance, the third component Eigen value is equal to 1.589 and explains $16 \%$ of the variance. Using parallel analysis, it was decided to retain only three factors for further investigation. As anticipated, these three factors emerge when factor analyzed using oblique rotation principal as shown in Table 2.3 for details see (Kim and Mueller, 1978; Schmitt, 2011). Oblamin method of rotation has been used from oblique rotation principal. According to (Fabrigar et al., 1999) there's no extensively ideal technique for oblique rotation, each and every one tend to create comparable results.

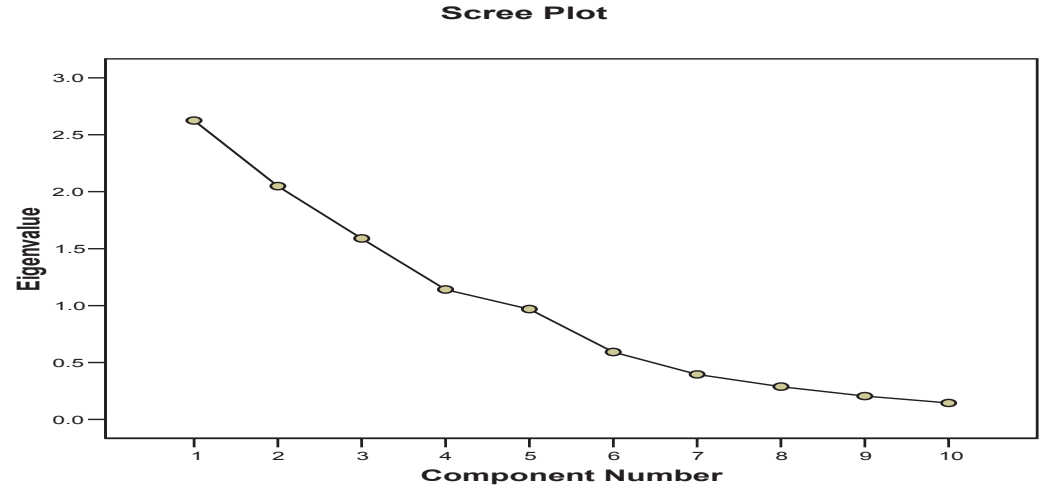


Table 2.2: Parallel analysis

\begin{tabular}{|c|c|c|c|}
\hline Component number & Eigenvalue from PCA & Value from Parallel analysis & Decision \\
\hline 1 & 2.624 & 1.7602 & Accept \\
\hline 2 & 2.049 & 1.5114 & Accept \\
\hline 3 & 1.589 & 1.3218 & Accept \\
\hline 4 & 1.141 & 1.1563 & Reject \\
\hline 5 & .969 & 1.0333 & Reject \\
\hline
\end{tabular}

Source: Own survey result

Table 2.3: Pattern and structure matrix for marketing performance items.

\begin{tabular}{|c|c|c|c|c|c|c|c|}
\hline \multirow{3}{*}{ Items } & \multirow{2}{*}{\multicolumn{3}{|c|}{$\begin{array}{c}\text { Pattern } \\
\text { coefficients } \\
\text { Component }\end{array}$}} & \multirow{2}{*}{\multicolumn{3}{|c|}{$\begin{array}{c}\text { Structure } \\
\text { coefficients } \\
\text { Component }\end{array}$}} & \multirow{3}{*}{ Communalities } \\
\hline & & & & & & & \\
\hline & 1 & 2 & 3 & 1 & 2 & 3 & \\
\hline We sustain customer loyalty through the unique marketing communication & .893 & -.173 & -.039 & .897 & -.200 & .015 & .835 \\
\hline We are doing a lot for customer satisfaction & .888 & -.035 & .049 & .892 & -.066 & .097 & .799 \\
\hline We place great emphasis on building long term relationship with key customers & .831 & .003 & .307 & .847 & -.036 & .350 & .812 \\
\hline We know how to do marketing & .388 & .090 & -.116 & .379 & .083 & -.099 & .166 \\
\hline We made extensive used of social media for promoting our products & .075 & .823 & -.223 & .037 & .830 & -.253 & .743 \\
\hline We are selling our products through a sales force & .064 & .797 & .148 & .046 & .789 & .119 & .650 \\
\hline We are using wholesalers and retailers to distribute our product & .034 & .777 & .058 & .012 & .773 & .028 & .603 \\
\hline We actively developed new product and after sale services to lead the market & -.096 & .328 & .005 & -.106 & .331 & -.014 & .119 \\
\hline $\begin{array}{l}\text { We always evaluated the consequences before doing something important, } \\
\text { relevant to marketing }\end{array}$ & .027 & .105 & .883 & .069 & .067 & .880 & .786 \\
\hline We don't prefer to watch and wait & -.006 & -.057 & .863 & .040 & -.092 & .865 & .751 \\
\hline
\end{tabular}

Note. Bold items indicate major factor loadings.

Source: Own survey result

Two specific forms of construct validity, convergent validity and discriminant validity were used for marble manufacturing unit marketing, the measures used in this study have been found to have acceptable convergent and discriminant validities. The Table above shows that the pattern of correlation that all three items of customer relation capability, three items of marketing coverage and two items of proactive marketing capability relate to their same constructs. Therefore, this correlation provides evidences that the items all converge on their same constructs.

Table above also shows that discriminant validity was ensured as the relationships between items and the rest of the factors is very low (see Table 2.3, structure matrix). The correlation confirmed that the measures that should not be related are in reality not related.

Table 2.4: Labeling of Factors

\begin{tabular}{|l|c|}
\hline Marketing & Factor loadings \\
\hline Factor one: Customer relation capability & \\
We sustain customer loyalty through the unique marketing communication & .893 \\
We are doing a lot for customer satisfaction & .888 \\
We place great emphasis on building long term relationship with key customers & .831 \\
Factor two: Marketing coverage & \\
We made extensive used of social media for promoting our products & .823 \\
We are selling our products through a sales force & .797 \\
We are using wholesalers and retailers to distribute our product & .777 \\
Factor three: Proactive marketing capability & \\
We always evaluated consequences before doing something important, relevant to marketing & .883 \\
We don't prefer to watch and wait & .863 \\
\hline
\end{tabular}

Source: Own survey result 
The dimensions construct of marble manufacturing unit marketing performance labels which are customer relation capability, marketing coverage, and proactive marketing capability as proposed by (Day, 1994; Vorhies et al, 2009; Morgan et al, 2003).

The items in Table 2.4 are factored in familiar component as for customer relation capability item 2, item 3, and item 1 , are consistently moving together and are in one group. Similarly, marketing coverage, such as item 7 , item 8 , and item 6 are in second clusters. While, proactive marketing capability group comprises of item 10, and item 9 . The item number has given based on their factor loading.

\section{Conclusion}

To answer the research question and achieve the research objective, this study conducted a principal component analysis (PCA) with an oblique rotation (direct oblimin). The ten items related to marketing were reduced to three factors using parallel analysis. The total variance of $62.6 \%$ is achieved for three factors. The first Eigen value is equal to 2.624 and explained $26.2 \%$ of the variance in the original data. The second factor Eigen value is equal to 2.049 and explains $20.4 \%$ of the variance, the third component Eigen value is equal to 1.589 and explains $16 \%$ of the variance. The pattern matrix has shown the existence of unpretentious structure with three factors, displaying the magnitude of strong factor loadings. The three factors were labeled as; customer relation capability, marketing coverage, and proactive marketing capability. Furthermore, the items are factored in their underlying factor as for the customer relation capability three items, namely, item 2, item 3, and item 1, are consistently moving together and are in one cluster. Similarly, marketing coverage group comprises of three items, such as item 7 , item 8 , and item 6 . Follow by a proactive marketing capability group which on the other hand, consists of two items, namely, item 10, and item 9 . The item number has given based on their factor loadings. Two items were dropped because of cross loading and low loading.

\section{1 limitations and future research opportunities}

To answer research question this study considered only EFAs and found the involvement of three factors from 8 items. This result leaves some gaps concerning CFA. It would be perhaps more expressive if the paper confirms the hypothetical model (Figure, 2). This study did not confirm that the identified factors confirmed as a dimension of marketing performance in the setting of marble manufacturing sector in KPK Province Pakistan but only propose hypothesize $2^{\text {nd }}$ order CFA model. We recommend the same nature of research with the consideration of CFA.

\subsection{Note}

There are numerous approaches to perform factor rotations. SPSS offers five, i.e. varimax, quartimax, equanmax, direct oblimin and promax. The first three types of factor rotations comes under orthogonal rotation. While the last two are from oblique rotation technique. Generally, oblimin factor rotation method is used from obique rotation technique and varimax is used from orthogonal rotation.

Hypothesize model for marketing performance (AMOS)

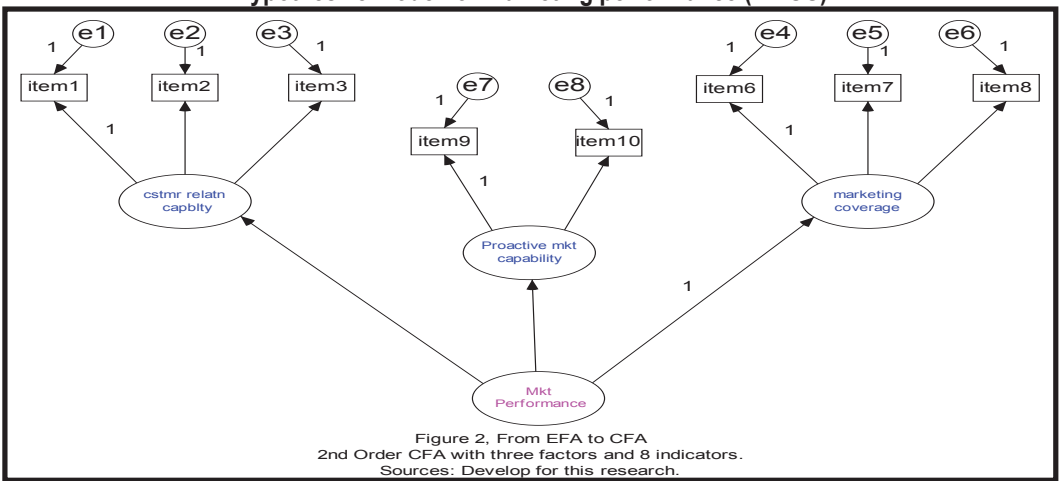




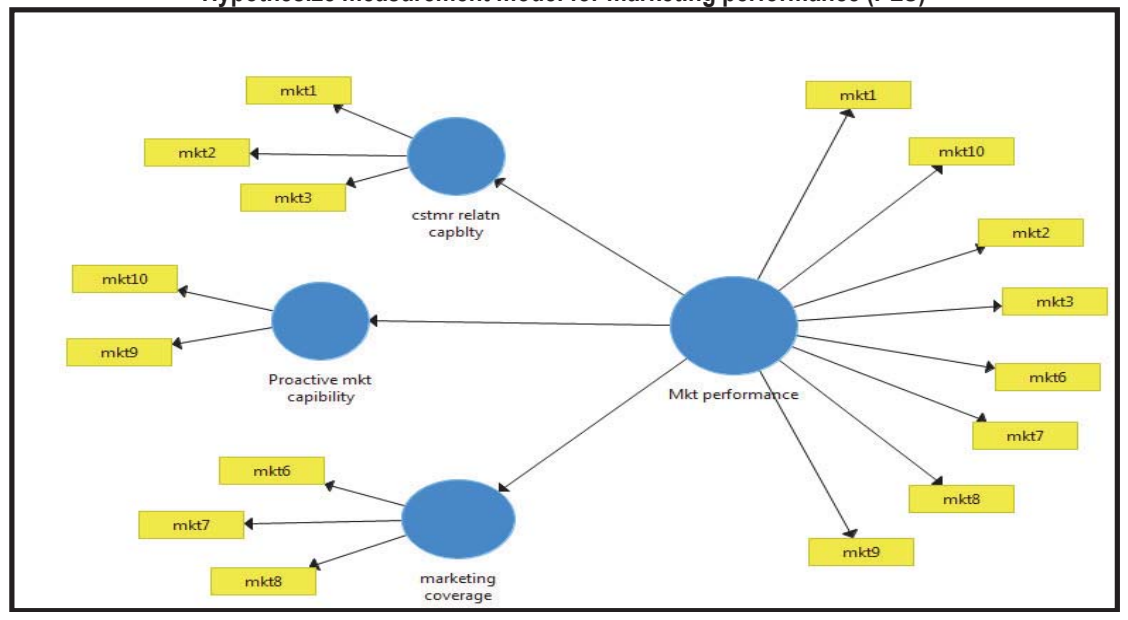

Source: Develop for this research

\section{References}

Bartlett, M. S. (1954). A note on the multiplying factors for various chi square approximation. Journal of Royal Statistical Society, 16(Series B), 296-8.

Brown, J. D. (2009c). Statistic Corner. Questions and answers about language testing statistics: Choosing the right number of components or factors in PCA and EFA. Shiken: JALT Testing \& Evaluation SIG Newsletter, 13(3), 19-25

Catell, R. R. (1966). The scree test for number of factors, Multivariate Behavioral Research, 1, 245-276.

Chin, W. W., Marcolin, B. L., \& Newsted, P. R (1996). A partial least squares latent variable modeling approach for measuring interaction effects: Results from a Mone Carlo simulation study and voice mail emotion /adaptation study. Paper presented at the $17^{\text {th }}$ International Conference on Information Systems, Clevelant, $\mathrm{OH}$.

Costello, A. B., \& Osborne, J. W. (2005). Best practices in exploratory factor analysis: Four recommendation for getting the most from your analysis. Practical Assessment, Research, and Evaluation, 10(7), 1-9.

Day, G.S. (1994). The capabilities of market driven organizations. Journal of Marketing, 58(4), 37-57. Press.

Fabrigar, I. R., Wegener. D. T., MacCallum, R. C. \& Strahan, E. J. (1999). Evaluating the use of exploratory factor analysis in psychological research. Psychological Methods, 4(3), 272- 299.

Field, A. (2000). Discovering Statistics using SPSS for Windows. London - Thousand Oaks - New Delhi: Sage publications.

Haenlein, M. \& Kaplan, A. M. (2004). A beginner's guide to partial least squares analysis, Undertandisng Statisticsm 3(4), 283-297.

Hair, J.F., Black, W.C., Babin, B.J., Anderson, R.E., \& Tatham, R.L. (2006).Multivariate data analysis (6th Ed.). Pearson Education International, Upper Saddle River.

Hair, J. F., Ringle, C. M., \& Mena, J., A. (2011). PLS-SEM: Indeed a silver bullet. Joournal of Marketing Theory and Practice, 19(2), 139151.

Hair, J. F., Sarstedt, M., Ringle, C., Mena, J., A. (2012). IAn Assessment of the Use of Partial Least Squares Structural Equation Modeling in Marketing Research. Journal of the Academy of Marketing Science, 40(3), 414-433.

Henseler, J., Ringle, C., \& Sinkovics, R. (2009). The use of partial least squares path modeling in international marketing. Advances in Internaltional Marketing, 20(2009), 277-320.

Horn,J. L. (1965). A rationale and test for the number of factors in factor analysis. Psychometrika, 30, 179-185.

Hutcheson, G. D., and Sofroniou, N. (1999). The Multivariate Social Scientist: an introduction to generalized linear models. Sage Publications.

Jarvis CB, Mackenzie SB, Podsako_PM (2003). A Critical Review of Construct Indicators and Measurement Model Misspecification in Marketing and Consumer research." Journal of Consumer Research, 30, 199-218.

Kaiser, H. (1970). A second generation Little Jiffy. Psychometrika, 35, 401-15.

Kaiser, H. (1974). An index of factorial simplicity. Psychometrika, 39, 31-6.

Kim, J. and Mueller, C. W. (1994). Factor Analysis: Statistical Methods and Practical Issues. In M. S. Lewis-Beck (editor). Factor Analysis and Related Techniques. International Handbooks of Quantitative Applications in the Social Sciences, Volume 5. Sage Publications. 
MacKenzie SB, Podsako_PM, Jarvis CB (2005). The Problem of Measurement Model Misspecification in Behavioral and Organizational Research and Some Recommended Solutions." Journal of Applied Psychology, 90(4), 710-730.

Morgan, N. A., Zou, S., Vorhies, D. W., \& Katsikeas, C. (2003). Experimental and information knowledge, architectural marketing capabilities and the adaptive performance of export venture: A cross national study, Decision Sciences, 34(2), 287-321.

Pallant, J. (2013). SPSS Survival Manual. A step by step guide to data analysis using SPSS, $4^{\text {th }}$ edition. Allen \& Unwin, www.allenandunwin.com/spss.

Rietveld, T. \& Van Hout, R. (1993). Statistical Techniques for the Study of Language and Language Behaviour. Berlin - New York: Mouton de Gruyter.

Schmitt, T. A. (2011). Current methodological considerations in exploratory and confirmatory factor analysis. Journal of Psychoeducational Assessment, 29(4), 304-321.

Stevens, J.P. (1992). Applied Multivariate Statistics for the Social Sciences (2nd edition). Hillsdale, NJ: Erlbaum.

Statsoft (2013). Stucture Equation Modeling, Statsoft Electronic Statistics Textbook. http://www.statsoft.com/textbook/structure-equationmodeling/

Tabachnick, BG \& Fidell, LS 1996, Using Multivariate Statistics (3rd Edn), Harper Collins: Northbridge, California.

Tabachnick, B. G. \& Fidell, L. S. (2007). Using multivariate statistics: Chicago: Univesity of Chicago Press.

Vorhies, D. W., Morgan, R. E., \& Autry, C. W. (2009). Product-market strategy and the marketing capabilities of the firm: Impact on market effectiveness and cash flow performance. Strategic Management Journal, 30(12), 1310-1334. 